\title{
QUEM MATOU FABIANE? - O IDEOLÓGICO QUE SURGE NA INTERNET REFRATADO NOS ATOS COTIDIANOS
}

Who killed Fabiane? - The ideological that appears on the internet refracted in everyday acts

¿Quién mató a Fabiane? - Ideológico que aparece en Internet refractada en actos cotidianos

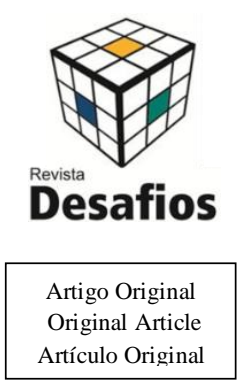

\author{
Lícia Frezza Pisa ${ }^{* 1}$, Ronivaldo Moreira De Souza². \\ ${ }^{1}$ Docente do curso de Produção Publicitária, Instituto Federal do Sul de Minas, Passos/MG, Brasil. \\ ${ }^{2}$ Doutorando em Comunicação Social da Universidade Metodista de São Paulo, SP, Brasil.
}

*Correspondência: Instituto Federal do Sul de Minas, Rua Mario Ribola, 409, Penha II, Passos, Minas Gerais, Brasil. CEP: 37.903-358, e-mail: licia.pisa@ifsuldeminas.edu.br

Artigo recebido em 08/01/2017. Aprovado em 10/02/2017. Publicado em 13/02/2017.

\section{RESUMO}

O presente trabalho investiga a ideologia presente nas enunciações jornalísticas divulgadas pela internet, analisando o caso do linchamento de Fabiane Maria de Jesus após a publicação de um retrato falado no perfil Guarujá Alerta, no Facebook. Por meio das noções de gênero, ideologia, alteridade e responsividade em Bakhtin, discute-se a ideologia da internet que, por ser um espaço de interação e diálogo, pode apresentar-se como uma monologia, no sentido de fechamento dos discursos. A pesquisa toma como corpus notícias divulgadas tanto nas redes sociais quanto na grande mídia, que antecederam e sucederam o incidente. Constata-se que as ideologias discursivas que permearam este fato refratam em atos do cotidiano o que é constituído como o ideológico da rede.

Palavras-chave: Gênero Jornalístico; Dialogismo; Fabiane Maria de Jesus.

\section{ABSTRACT}

This study investigates the ideology present in journalistic utterances disclosed by Internet, analyzing the case of lynching Fabiane Maria de Jesus after the publication of a sketch in Guaruja Alert profile on Facebook. Through the notions of gender, ideology, otherness and responsiveness in Bakhtin discusses the ideology of the internet that, as a space for interaction and dialogue, can present as a monologia, to closing speeches. The research takes as corpus news published both on social networks and in the mainstream media, leading up to and followed the incident. It appears that the discursive ideologies that permeated this fact refract in everyday acts which is constituted as the ideological network.

Keywords: Press Gender; Dialogism; Fabiane Maria de Jesus.

\section{RESUMEN}

Este estudio consiste en el presente la ideología en los enunciados periodísticos publicados en Internet, analizando el caso de linchamiento Fabiane María de Jesús después de la publicación de un boceto en el perfil de alerta Guaruja en Facebook. A través de las nociones de género, la ideología, la alteridad y la capacidad de respuesta en Bajtin habla de la ideología de la Internet, que, al ser un espacio de diálogo y la interacción puede ser presentado como un monologia, a los discursos de cierre. La investigación toma como informes de noticias corpus tanto en las redes sociales y en los medios de comunicación, que precedieron y siguieron al incidente. Parece ser que las ideologías discursivas que impregnaron este hecho se refractan en actos cotidianos que se constituye como la red ideológica.

Descriptores: Género periodístico; dialogismo; Fabiane María de Jesús. 


\section{INTRODUÇÃO}

Em três de maio de 2014 foi noticiado em vários veículos no Brasil a morte por linchamento de Fabiane Maria de Jesus. A morte ocorreu devido a uma notícia com uma foto, divulgada pelo perfil do Facebook Guarujá Alerta, em que uma moradora da favela de Morrinhos estaria aliciando crianças para magia negra. Fabiane foi confundida com a pessoa da foto divulgada e, por isso, morta por populares.

A partir desse fato, esta pesquisa retoma alguns conceitos bakhtinianos para investigar o incidente e sua ligação com as abordagens noticiosas anteriores e posteriores que permitem acessar uma ideologia valorativa do conteúdo noticioso da web e como se dá essa valoração; assim como compreender o diálogo que se desenha entre sociedade e este meio, em que as possibilidades de interação são múltiplas, porém, o que se percebe, nesse caso específico, é um silenciamento da voz do outro naquilo que é divulgado pela rede, e o fato realmente constituído. A proposta é chegar a uma percepção mais aguçada de como o conteúdo online é capaz de influenciar os atos cotidianos off-line.

\section{PRESSUPOSTOS TEÓRICOS: A QUESTÃO DO GÊNERO EM BAKHTIN}

Bakhtin (1997) propõe pensar a linguagem dialógica nas mais variadas esferas sociais e o gênero seria a maneira de se compreender a dialogicidade, a intertextualidade, o ideológico e o estilo nos textos, assim, cada esfera da atividade humana comporta variedades linguísticas e discursos.

Essas esferas estão interrelacionadas e exercem influência na formatação dos gêneros no que diz respeito, especificamente, ao tema, estilo e à estrutura composicional. Cada esfera da comunicação conhece seus gêneros, que são apropriados à sua especificidade e aos quais correspondem determinados estilos: "qualquer enunciado considerado isoladamente é, claro, individual, mas cada esfera de utilização da língua elabora seus tipos relativamente estáveis de enunciados, sendo isso o que denominamos gêneros do discurso" (BAKHTIN, 1997, p. 279).

Bakhtin (1997) toma o enunciado como a base do gênero discursivo. $\mathrm{O}$ autor destaca que os gêneros são tipos relativamente estáveis de enunciados, marcados pela especificidade de uma esfera/grupo de comunicação e pela valoração dos sujeitos (pela sua expressividade), tendo em vista que "os gêneros do discurso, são as correias de transmissão que levam da história da sociedade à história da língua" (BAKHTIN, 1997, p. 285). Exemplificando, os gêneros do discurso podem ser entendidos como uma curta réplica do diálogo cotidiano, relato familiar, carta, ordem militar, documentos oficiais, declaração pública, formas de exposição científica, modelos literários, publicitários etc. Os gêneros sofrem modificações de acordo com o momento histórico em que estão inseridos, em vista disso são relativamente estáveis e são também correias de transmissão, pois assim levam a história da sociedade nos seus enunciados.

Dessa maneira, o gênero não pode ser pensado fora da dimensão espaço-temporal, pois enquanto o espaço é social, o tempo é histórico e os gêneros surgem dentro de algumas tradições com as quais se relacionam de algum modo, permitindo a reconstrução da imagem espaço-temporal da representação que orienta a utilização da linguagem. Os discursos presentes em cada tipo de gênero apontam para as várias formas de dialogismo, de polifonia, de intertextualidade que configuram a natureza própria dos enunciados. Para o autor, ignorar 
a natureza dos discursos é o mesmo que apagar a ligação que existe entre a linguagem e a vida.

\section{A classificação dos gêneros}

Os estudos tradicionais, como os de Platão e Aristóteles, davam destaque apenas para os gêneros literários (épico, dramático e lírico) e os gêneros retóricos (jurídicos e políticos); Bakhtin, porém, considera o dialogismo do processo comunicativo inserido nos mais diversos campos de possibilidades da comunicação. Para Machado (2007, p. 152),

a partir dos estudos de Bakhtin foi possível mudar a rota dos estudos sobre os gêneros: além das formações poéticas, Bakhtin afirma a necessidade de um exame circunstanciado não apenas da retórica mas, sobretudo, das práticas prosaicas que diferentes usos da linguagem fazem do discurso, oferecendo-o como manifestação de pluralidade.

Bakhtin classifica os gêneros em primário (simples) e secundário (complexo) ${ }^{1}$, sendo atravessados por ideologias variadas que se materializam na enunciação. Os gêneros primários seriam aqueles que nascem das conversas informais no cotidiano e que mantêm uma relação imediata com as situações nas quais são produzidos: a conversa das donas-de-casa, os encontros casuais pelas ruas, a conversa de salão, a carta, o relato cotidiano etc. Já o gênero secundário seria fruto da comunicação produzida a partir de códigos culturais elaborados em situações de troca cultural "mais complexa e mais evoluída", constituídos pelos gêneros principalmente da escrita, desenvolvidos nas áreas artística, científica, sócio-política.

\section{A relação entre estilo e gênero}

\footnotetext{
${ }^{1}$ Será utilizada a nomenclatura gênero primário e gênero secundário de acordo com Bakhtin (1997).
}

Bakhtin trata em seu texto sobre a teoria do romance, Questões de Literatura e de Estética (1998), a questão do estilo. $\mathrm{O}$ gênero possui três características que estão intrinsecamente ligadas e que o caracterizam: estrutura composicional, tema e estilo.

O estilo é um fator determinante para o gênero, pois, "quando há estilo, há gênero" (BAKHTIN, 1997, p. 286) e, assim, tema, estilo e estrutura composicional interagem construindo uma formatação plástica, visto que os gêneros são relativamente estáveis.

O estilo está ligado tanto ao gênero enquanto estilo linguístico que "nada mais é senão o estilo de um gênero peculiar a uma dada esfera da atividade e da comunicação humana" (BAKHTIN, 1997, p. 283); como ao tema como "tipo de estruturação e de conclusão de um todo, tipo de relação entre o locutor e os outros parceiros da comunicação verbal (relação com o ouvinte, ou com o leitor, com o interlocutor, com o discurso do outro, etc." (BAKHTIN, 1997, p. 284). Também vincula-se ao sujeito, à expressividade e entonação, que têm relação com a maneira pela qual os sujeitos avaliam seu projeto discursivo, seus interlocutores.

O estilo é o fator que determina a identidade dos gêneros, sendo fornecido por certos agrupamentos. Nas palavras de Bakhtin,

cada época histórica da vida ideológica e verbal, cada geração, em cada uma das suas camadas sociais, tem a sua linguagem: ademais, cada idade tem a sua linguagem, seu vocabulário, seus sistemas de acentos específicos, os quais, por sua vez, variam em função da camada social, do estabelecimento de ensino (a linguagem do cadete, do ginasiano, do realista são linguagens diferentes) e de outros fatores de estratificação. Trata-se de linguagens socialmente típicas por mais restrito que seja o seu meio social. É possível considerar como social, ao limite, mesmo um jargão 
familiar como, por exemplo, o jargão da família Irtiénhiev, representado por Tolstoi, com seu vocabulário próprio e com seu sistema de acento específico (1998, p. 98).

Nos estudos sobre o romance, Bakhtin tratou do dialogismo entre estilos. Há, por exemplo, os gêneros individuais presentes nas falas das diferentes personagens que se unem na totalidade da obra para conferir estilo ao todo e "carrega o acento desse todo, toma parte na estrutura e na revelação do sentido único desse todo" (BAKHTIN, 1998, p. 74). Assim, temos o estilo do gênero e o estilo no gênero, com referências individuais em que a voz do autor aparece, em certos casos, com mais especificidade. $\mathrm{O}$ estilo, reiterando, pode ser tanto individual, marcado pela singularidade, quanto coletivo, em que há a especificidade estável de cada gênero.

Os gêneros literários, na visão bakhtiniana, são os mais propícios para se visualizar os estilos, dado que neles o estilo individual "faz parte do empreendimento enunciativo enquanto tal e constitui uma das suas linhas diretrizes" (BAKHTIN, 1997, p. 283). Já certos gêneros secundários do discurso apresentam condições desfavoráveis para se refletir a individualidade do estilo na língua, pois a sua natureza requer uma certa padronização, como, por exemplo, a formulação do documento oficial, a ordem militar, a nota de serviço em que o estilo do autor não é relevante.

É necessário ressaltar que o estilo é suscetível de mudanças e quando muda, a estrutura e o tema se moldam de modo coerente ao estilo.

\section{Gênero e ideologia}

A investigação dos gêneros do discurso implica, também, a identificação das relações entre as diferentes ideologias circulantes nos gêneros. Essas relações ideológicas materializam-se nos discursos, que incorporam finalidades e destinatários: "tudo o que é ideológico possui um significado e remete a algo situado fora de si mesmo" (BAKHTIN, 2002, p. $31)$.

A ideologia, como coloca o Círculo de Bakhtin, "brota e é constituída nos encontros casuais e fortuitos, no lugar do nascedouro dos sistemas de referência, na proximidade social com as condições de produção" (BRAIT, 2007, p. 169). Para entendermos $\mathrm{o}$ funcionamento da ideologia, materializada no discurso, é necessário a compreensão da realidade sócio histórica em que estão inseridos o locutor e os interlocutores desse discurso, pois para Bakhtin,

um produto ideológico faz parte de uma realidade (natural ou social) como todo corpo físico, instrumento de produção ou produto de consumo; mas, ao contrário destes, ele também reflete e refrata uma outra realidade, que lhe é exterior (2002, p. $31)$.

Como os sistemas culturais, sociais, econômicos estão em constante mudança, os signos e as ideologias acompanham/produzem essas mudanças. Para Bakhtin, "a palavra veicula, de maneira privilegiada, a ideologia; a ideologia é uma superestrutura, as transformações sociais da base refletem-se na ideologia e, portanto, na língua que as veicula" (2002, p. 17). Miotello explica ideologia oficial e ideologia do cotidiano nos seguintes termos:

a ideologia oficial é entendida como relativamente dominante, procurando implantar uma concepção única de reprodução do mundo. A ideologia do cotidiano é considerada como a que brota e é constituída nos encontros casuais e fortuitos, no lugar do nascedouro dos sistemas de referência, na proximidade social com as condições de produção e reprodução da vida (2008, p. 168-169). 
Percebe-se que a ideologia do cotidiano é, por natureza, dialógica tanto na dimensão da produção quanto da reprodução, dado ao seu engajamento com o social.

\section{A ideologia e o dialogismo}

Para Bakhtin, o cerne das ideologias está na interação. Tudo está em diálogo, por isso, o termo dialogismo. Dialogismo é um princípio inerente ao funcionamento social da linguagem $e$, consequentemente, responsável pela produção de sentidos do discurso. O dialogismo é concebido na relação entre o eu e o tu e entre o eu e o outro, ambos socialmente organizados. O outro para Bakhtin tem um papel importante nessa interação, visto que ele valida/constitui o sentido, estabelece a alteridade.

As relações dialógicas, ao serem travadas entre línguas, sentidos e vozes sociais, evidenciam a coexistência de uma pluralidade de manifestações discursivas, que se materializam na noção de heteroglossia, entendida como a interação de múltiplas perspectivas individuais e sociais, representando uma estratificação da linguagem, ou seja, mostra o quanto não somos autores soberanos das palavras que proferimos. A forma como nos expressamos está sempre impregnada de contextos, estilos e intenções distintas, marcadas pelo meio e pelo tempo em que vivemos.

Em contraponto à dialogia está a monologia. O monológico é aquilo que se apresenta como acabado, impositivo e que, geralmente, produz o apagamento ou fechamento do outro e de outros discursos. A palavra do outro se torna anônima: “esquece-se completamente a relação dialógica original com a palavra do outro: esta relação parece incorporar-se, assimilar-se à palavra do outro tornada familiar" (BAKHTIN, 1974, p. 406).

O dialogismo também está relacionado à questão da identidade: as identidades não existem de forma independente ou soberana, mas são frutos de um processo (interacional) histórico, social, cultural e discursivo. Os sujeitos compartilham crenças, valores, padrões cognitivos e linguísticos que remetem a grupos sociais ou a variadas ideologias circulantes, tendo como referência sempre um outro: "um grupo social se reconhece como tal através de um processo complexo de diferenciação a respeito do que é diferente" (PONZIO, 2008, p. 24).

Nesse sentido, a relação com a alteridade é constitutiva de um discurso identitário, na medida em que este se elabora a partir do confronto entre diferentes visões de mundo, pensamentos, opiniões, verdades, modos de ser, etc.

Pensando numa identidade social que começa a florescer no gênero jornalístico, trazemos a expressão "justiça com as próprias mãos", sendo esta uma possibilidade de alteridade à ideia de um sistema judiciário lento ou que não funciona, ou mesmo de um Estado que não protege sua população, ou seja, há uma esfera, um grupo social que, com seus diálogos cotidianos, se constitui e é esse "horizonte social definido e estabelecido que determina a criação ideológica do grupo social e da época a que pertencemos" (BAKHTIN, 2006, p. 116).

\section{CARACTERÍSTICAS CONSTITUTIVAS DO GÊNERO JORNALÍSTICO}

Não é proposta desta sessão estabelecer uma tipologia rígida para enquadrar e classificar o gênero jornalístico, já que o próprio Bakhtin admite uma heterogeneidade constitutiva dos gêneros, orientando uma investigação ancorada no contexto históricosocial de um dado gênero tomado como objeto (BAKHTIN, 1997, p. 281-282). Admite-se, no entanto, situar o gênero na categoria de gênero secundário. 
O que se objetiva aqui é a investigação do caráter dialógico que compõe o gênero jornalístico, sua proposta (re)produtora da vida cotidiana e os efeitos de verdade que legitimam o fazer jornalístico.

\section{Entre o fato e a notícia}

Segundo Acosta (2011, p. 10), partindo dos conceitos de Bakhtin, é possível definir que "o projeto sociodiscursivo da notícia é renunciar acontecimentos atuais da vida social, isto é, noticiar os fatos da atualidade". Nesta definição percebe-se a estreita ligação entre o fazer jornalístico e a cotidianidade.

Sobre esta relação intrincada, Berger e Tavares afirmam que o jornalismo não apenas vê o mundo, mas, interpreta-o valendo-se de recursos entrelaçados por lógicas institucionalizadas e legitimadas de apreensão do cotidiano, "que funcionam como uma espécie de metodologia para se pensar a realidade, produzindo, por consequência, um tipo de conhecimento sobre ela" (2014, p. 14). E acrescenta:

A linguagem jornalística, concretizada a partir de um conjunto de técnicas e significantes (textuais, imagéticos, materiais e editoriais), coloca em cena os traços da subjetividade que permeiam a profissão e a mediação que a perpassa [...]. Ao falar do mundo, no mundo e para o mundo, o jornalismo realiza um arranjo de sentidos, potencialmente múltiplos, que incide sobre a interpretação que ele realiza e sobre o conhecimento que produz (BERGER; TAVARES, 2014, p. 15).

Nesse processo complexo e cerceado por ideologias, tanto as institucionalizadas pela instância midiática quanto aquelas presentes na própria formação sócio histórica do jornalista, há que se considerar o funcionamento que permite ao dizer noticioso galgar o status de verdade, legitimada e autenticada.
Charaudeau (2010) levanta a problemática de que ao assumir a prerrogativa de dizer o que aconteceu, as mídias informativas assumem o lapso temporal entre o dito e o fato, ou seja, o relato que liga estas duas instâncias só pode se inscrever no campo da reconstituição. Assim sendo, a questão que se coloca é a da veracidade desta reconstituição, o grau de verossimilhança capaz de fazer crer que o dito é fiel ao fato tal como se realizou. Segundo o autor, o processo que permite atingir essa forma de verdade é o da "analogia", que consiste em descrever o mundo segundo roteiros de verossimilhança, possibilitando que "ao término desse procedimento de reconstituição a mídia possa dizer, por exemplo: "eis como o sequestrador agiu" (2010, p. 89). O autor conclui:

no discurso de informação, entretanto, não se trata da verdade em si, mas da verdade ligada à maneira de reportar os fatos: não é bem das condições de emergência da verdade que se trata, mas sim das condições de veracidade. À instância midiática cabe autenticar os fatos, descrevê-los de maneira verossímil, sugerir as causas e justificar as explicações dadas (CHARAUDEAU, 2010, p. 88).

Unindo estas perspectivas pode-se afirmar que o gênero jornalístico caracteriza-se pela (re)constituição, pois, em sua proposta ideológica de reconstituir os fatos por meio da notícia, acaba, na notícia, constituindo os fatos:

a ideologia espelha a ordem social, ao mesmo tempo que não permite a compreensão da sua própria constituição sócio histórica; a utopia, por sua vez, mira na dissolução dessa ordem pela projeção de uma visão alternativa da existência. A tensão dialética entre esses dois fenômenos resulta na permanente oscilação entre fantasia e prática, entre escapar e voltar (GARDINER, 2008, p. 222). 
Assim sendo, a estreita ligação entre o fazer jornalístico e a ideologia fica evidente quando o gênero jornalístico assume a posição de um espelho da vida social. Considerando-se a dimensão fantasiosa entre o espelho e o objeto refletido (já que o espelho não apresenta o objeto, mas, a imagem do objeto).

\section{O CASO DE FABIANE MARIA DE JESUS}

O caso que será analisado é o da Fabiane Maria de Jesus, moradora da favela de Morrinhos na cidade de Guarujá, litoral paulista, casada, mãe de duas filhas, diagnosticada com transtorno bipolar e morta por espancamento por moradores por um possível boato de que ela seria sequestradora de crianças para rituais de magia negra. Depois de sua morte foi constatado que ela havia sido confundida por causa de um retrato falado divulgado no Facebook no perfil Guarujá Alerta. Segundo contam, Fabiane andava carregando uma Bíblia e, ao ser abordada por populares, não teve tempo de falar.

\section{A ideologia da rede}

"Mataram a mulher", é a mesma cara [do retrato falado] ${ }^{2}$ do Guarujá Alerta, um perfil no Facebook. Esse é o título da matéria divulgada do caderno Cotidiano da Folha de São Paulo em 5 de maio de 2014 (CAMPANHA, 2014).

É possível compreender a responsabilidade da comunicação em rede, capaz de mobilizar um número grande de pessoas em favor de determinadas situações, porém, o que se percebe é que a possibilidade do diálogo, da réplica, da tréplica é silenciada por atos não reflexivos, não dialógicos, que fecham o pensamento e acabam em atitudes bárbaras.

\footnotetext{
${ }^{2}$ Disponível em:< http://www1.folha.uol.com.br/cotidiano/2014/05/1449679mataram-a-mulher-diz-morador-apos-espancamento-noguaruja-veja-video.shtml>. Acesso em 30 maio 2014.
}

A teoria dialógica de Bakhtin mostra o caráter responsivo ativo das apresentações/enunciações, não postulando o receptor como ser passivo das mensagens, mas considerando-o como um sujeito que estabelece relações dialógicas com os enunciados que o interpelam, e com os quais concorda, aceita ou refuta e discorda:

(...) cada enunciado deve ser visto antes de tudo como uma resposta aos enunciados precedentes de um determinado campo: ela os rejeita, confirma completa, baseia-se neles, subtende-os como conhecidos, de certo modo os leva em conta. Porque o enunciado ocupa uma posição definida em uma dada esfera da comunicação, em que dada questão, em um dado assunto, etc. É impossível alguém definir sua posição sem correlacioná-las com outras posições. Por isso, cada enunciado é pleno de variadas atitudes responsivas a outros enunciados, de doutra esfera da comunicação discursiva (BAKHTIN, 1997, p. 297).

O que podemos perceber é que não houve o diálogo entre o boato e o ato dos moradores e, sendo o ideológico um produto inteiramente social (PONZIO, 2008, p. 109), faz-se necessário compreender essa ideologia em diálogo na sociedade brasileira. Por que isso aconteceu? Qual contexto social poderia dialogar com o fato? Arrisca-se pensar que num ambiente de múltiplas possibilidades de interação e comunicação, o discurso da internet produz um efeito de verdade inviolável, ou seja, o dialogismo está sendo suprimido pelo monologismo e, a monologia fecha o pensamento (MIOTELLO, 2009), silencia a reflexão e parece haver um discurso de que na internet é possível fazer tudo. E, se não ocorre um diálogo em que é possível procurar compreender o fato depois do dito, busca-se um culpado para tal crime: "a culpa foi da internet", disseram algumas testemunhas que prestaram depoimento à polícia (GORCZESKI, 2014, p. 42). O perfil no Facebook Guarujá Alerta foi apontado por 
muitos como o grande culpado, o que é um paradoxo, pois até então o perfil tinha a intenção de alertar aquela população de possíveis situações que poderiam estar acontecendo na comunidade e região (BANCALEIRO, 2014) e, de repente, passa a ser o culpado, justamente, por divulgar informações. Segundo Cristina Sleiman, advogada do Guarujá Alerta, o perfil só poderia ser acusado caso tivesse publicado uma foto ou o nome da Fabiane.

Por outro lado, com o ocorrido, há um discurso da "justiça com as próprias mãos" que pode ter embalado as ações dos moradores.

\section{Ideologia "justiça com as próprias mãos"}

Concomitantemente ao caso de Fabiane, jornais brasileiros noticiavam a questão da justiça com as próprias mãos. Grupos de cidadãos comuns ao serem vítimas de assaltos ou atos criminosos estariam prendendo e espancando o algoz. Isso gerou muita polêmica, principalmente pelo depoimento da jornalista do SBT, Raquel Sheherazade, sobre os justiceiros no Rio de Janeiro, em que vítimas prenderam a um poste um garoto que havia cometido um roubo. Segue sua fala:

O Estado é omisso, a polícia desmoralizada, a justiça é falha. O que resta ao cidadão de bem que ainda por cima foi desarmado? Se defender é claro. O contra-ataque aos bandidos é o que eu chamo de legítima defesa coletiva de uma sociedade sem Estado contra um estado de violência sem limite $^{3}$.

Esse depoimento teria dialogado com o crime de Fabiane no sentido de que o cidadão comum quer se defender por não encontrar no Estado a segurança

\footnotetext{
${ }^{3}$ Disponível em http://www.youtube.com/watch?v=unVIpQHLDwE. Acesso em 30 maio 2014.
}

necessária? Fazer justiça com as próprias mãos seria um ato ideológico de segurança e sobrevivência?

Para Hirschkop (2008, p. 103), “o dialogismo só é concebível dado um estado de luta ideológica; esta é a forma como ele se conecta a forças sociais e projetos não discursivos" (HIRSCHKOP, 2008, p. 103). É preciso lembrar também que, segundo Newcomb (2010, p. 383), "numa abordagem dialógica da comunicação de massa, o discurso não é "dado". Ele é criado", e muitas forças ideológicas poderiam ter motivado as falas da jornalista, o que não inviabiliza compreender os atos dos moradores na morte de Fabiane.

O que parece estar havendo é uma cristalização do pensamento, no sentido de não questionar o que está sendo divulgado e, se todo ato é responsivo, a responsividade está sendo sufocada por uma identidade de luta em que a justiça não adentra os problemas sociais, não ouve o cidadão e não the presta nenhuma atenção básica, pois "o dialogismo não é uma função da singularidade dos indivíduos ou de momentos históricos; está fundamentado nas divisões estruturais da vida social e histórica" (HIRSCHKOP, 2008, p. 105). Ainda segundo Hirschkop (2008, p. 111):

a lógica do carnaval, detalhadamente descrita em A cultura popular na Idade Média e no Renascimento - o contexto de François Rabelais, é determinada pela estratégia ideológica de oposição à classe dominante no feudalismo. São as condições de luta ideológica, no lugar das atitudes subjetivas, que definem a forma tomada pelo dialogismo e pelo monologismo.

Seria essa inversão entre dialogismo e monologismo que pautou a morte de Fabiane? Seria essa a questão dialógica entre sociedade e Estado como tratado pela jornalista Sheherazade? 


\section{Ideologia da inocência}

Depois de noticiada a morte de Fabiane e de que ela era inocente, muitas pessoas no protesto que fizeram sobre sua morte estamparam nas camisetas: "A dor da inocência". Em matéria da revista Época aparece: "a selvageria que matou uma dona de casa inocente" (GORCZESKI, 2014, p. 38).

E se ela fosse culpada, justificaria a morte por linchamento? O que a linguagem nos traz, sendo a palavra um "fenômeno ideológico por excelência" (BAKHTIN, 2002, p. 36), é um retrato de como a sociedade está dialogando com certos fatos. Ao dizer que ela era inocente apenas afirma a ideologia da violência, da justiça com as próprias mãos. Fica implícito que se ela realmente tivesse sequestrado as crianças sua morte seria justificada e heroica? Segundo o advogado da família em matéria de Rossi (2014), "foi uma barbárie cometida por uma injustiça”, mas a barbárie por justiça também não é justificável, ou seja, ao enaltecer a inocência de Fabiane deixa implícito a ideologia de que é aceitável agir fora da lei, pois, o erro não seria matar, mas matar a pessoa errada.

\section{CONCLUSÃO}

Os gêneros do discurso circulam socialmente e os gêneros secundários estão intercalados na produção jornalística quando produzem textos sobre a vida cotidiana, porém, ao serem inseridos no gênero secundário se desligam da esfera do cotidiano, perdem sua ligação direta com a realidade, deixam de ser acontecimento da vida cotidiana e passam a fazer parte de outra dimensão enunciativa e ideológica.

Quando ancorada no contexto sócio histórico, a expressão “justiça com as próprias mãos" é ideológica no sentido de ter uma intenção de segurança, ou seja, a violência é justificada. Do mesmo modo quando se fala em inocência, a violência continua a ser justificada, pois o ato de matar não é questionado e, sim, se foi a pessoa certa ou não.

A questão sobre a qual deve-se refletir é: e se isso se tornar uma identidade e, assim, a falta de controle do Estado em garantir segurança à população se tornar recorrente instaurando um "salve-se quem puder" totalmente desacreditado nas leis e no sistema judiciário? O diálogo entre população e Estado deixa transparecer que a "alteridade ideológica está sufocada pela identidade" (PONZIO, 2008, p. 26).

A ação dos moradores silencia o ato reflexivo, responsivo da palavra e da alteridade do outro e, nesse momento, a atividade da multidão se torna utopia enquanto alternativa, contra a lei, para se viver. O outro, ou seja, a população, que deveria validar o sentido do que é veiculado na internet, acaba sendo suprimida pela omissão da própria reflexão e ato responsivo, tomando as veiculações na internet com tom de verdade. $\mathrm{E}$ essa ideologia espelha uma certa ordem social a que estamos vendo acontecer e, por isso, marca um tempo e um espaço.

Todos os autores declararam não haver qualquer potencial conflito de interesses referente a este artigo.

\section{REFERÊNCIAS}

ACOSTA, Rodrigo. O gênero jornalístico notícia impressa: dialogismo, avaliatividade e estilo. Revista de Letras, n. 14, Departamento Acadêmico de Comunicação e Expressão (DACEX). Curitiba-PR: UTFPR. 2011. Disponível em: http://www.dacex.ct.utfpr.edu.br/14\%200\%20g\%C3 \%AAnero\%20jornal\%C3\% ADstico\%20not\%C3\%A Dcia\%20impressa.pdf. Acesso em fev. 2014.

BAKHTIN, Mikhail. Os Gêneros do Discurso. São Paulo: Martins Fontes, 1952. In: BAKHTIN, Mikhail. Estética da Criação Verbal. Trad.: Maria Ermantina Galvão G. Pereira. São Paulo: Martins Fontes, 1997.

Questões de Literatura e de Estética: a teoria do romance. 4. ed. São Paulo: Hucitec, 1998. 
Marxismo e Filosofia da Linguagem. 12. ed. São Paulo: Hucitec, 2006.

Observações sobre a epistemologia das ciências humanas. São Paulo: Martins Fontes, 1974. In: Estética da Criação Verbal. Trad. Maria Ermantina Galvão G. Pereira. 2. ed. São Paulo: Martins Fontes, 1997.

BANCALEIRO, Cláudia. Brasileira morre após espancamento devido a rumor falso no Facebook. Mundo P, Portugal, 09 maio 2014. Caderno Mundo. Disponível em:< http://www.publico.pt/mundo/noticia/brasileiramorre-apos-espancamento-devido-a-rumor-falso-nofacebook-1635322\#/0>. Acesso em 30 maio 2014.

BRAIT, Beth. Bakhtin: conceitos-chave. 4. ed. São Paulo, 2007.

BERGER, Christa. TAVARES, Frederico de Mello Brandão. Leituras do cotidiano e as interseções entre o jornalismo e as ciências sociais. Contemporânea, Comunicação e Cultura, v. 12, n. 01, p. 8-26, jan. abr. 2014.

CAMPANHA, Diógenes. 'Mataram a mulher', diz morador após espancamento em Guarujá. Folha de São Paulo, São Paulo, 5 maio 2014. Caderno Cotidiano. Disponível em: <http://www1.folha.uol.com.br/cotidiano/2014/05/14 49679-mataram-a-mulher-diz-moradoraposespancamento-no-guaruja-veja-video.shtml>. Acesso em 30 maio 2014.

CHARAUDEAU, Patrick. Discurso das mídias. São Paulo: Contexto, 2010.

GARDINER, Michael. O carnaval de Bakhtin: a utopia como crítica. In: RIBEIRO, Ana Paula
Goulart; SACRAMENTO, Igor. Mikhail Bakhtin: linguagem, cultura e mídia. São Carlos: Pedro e João Editores, 2010. 430p.

GORCZESKI, Vinícius. Selvageria, medo e ignorância. Época, Rio de Janeiro, v. [s.d.], n. 832, p. 38-42, 12 maio 2014.

HIRSCHKOP, Ken. Bakhtin, discurso e democracia. In: RIBEIRO, Ana Paula Goulart; SACRAMENTO, Igor. Mikhail Bakhtin: linguagem, cultura e mídia. São Carlos: Pedro e João Editores, 2010. 430p.

MIOTELLO, Valdemir. Ideologia. In: BRAIT, Beth (org.). Bakhtin: conceitos-chave. São Paulo: Contexto, 2008.

MIOTELLO, Valdemir (Org.). Dialogismo: olhares, vozes, lugares. São Carlos: Pedro e João Editores, 2009.

NEWCOMB, Horace. Sobre aspectos dialógicos da comunicação de massa. In: RIBEIRO, Ana Paula Goulart; SACRAMENTO, Igor. Mikhail Bakhtin: linguagem, cultura e mídia. São Carlos: Pedro e João Editores, 2010. 430p.

PONZIO, Augusto. A revolução bakhtiniana: o pensamento de Bakhtin e a ideologia contemporânea. Coord. Tradução Valdemir Miotello. São Paulo: Contexto, 2008.

ROSSI, Mariane. Mulher espancada após boatos em rede social morre em Guarujá, SP. G1, Santos e Região, 5 maio 2014. Disponível em:< http://g1.globo.com/sp/santosregiao/noticia/2014/05/mulher-espancada-aposboatos-em-rede-social-morre-em-guaruja-sp.html> . Acesso em 30 maio 2014. 